\title{
Exploring the Relationship between Impression Management, Emotional Intelligence and Locus of Control: Evidence from Egypt
}

\author{
Tarek A. El Badawy (Corresponding author) \\ Business Administration Department, Auburn University at Montgomery \\ Alabama, USA \\ E-mail: tarek.elbadawy@aum.edu \\ Mariam M. Magdy \\ German University in Cairo, Egypt \\ Email: mariam.ahmed-magdy@guc.edu.eg
}

Received: January 13, 2017 Accepted: February 06, 2017 Published: February 18, 2017 doi:10.5296/ijhrs.v7i1.10603 URL: http://dx.doi.org/10.5296/ijhrs.v7i1.10603

\begin{abstract}
Research on impression management is still in the infancy stage. The aim of this study was to explore the interaction between impression management and two organizational variables, namely emotional intelligence and locus of control. A sample of 106 participants was extracted from the Egyptian working population. The analysis was conducted using Spearman Rho's. Results indicated insignificant correlation between impression management and emotional intelligence. A weak association was found between impression management and external locus of control and an insignificant, yet negative, correlation was found between emotional intelligence and locus of control. Further analyses, implications and future research recommendations are provided.
\end{abstract}

Keywords: Impression Management; Emotional Intelligence; Locus of Control; Egypt; Self-presentation. 


\section{Introduction}

The concept of impression management was first coined by Erving Goffman in the 1950s. It is defined as the individual's attempt to manipulate how others see him/her as if the individual is an actor on stage trying to convey a certain character. Since then, researchers started to study impression management and try to map it with other organizational constructs. Some tried to explain its antecedents and outcomes. Others tried to measure its impact. Another group of researchers tried to question its integrity.

However, the human behaviour is not static. Constructs developed within the organizational behaviour field are related and interconnected. This makes the study of human behaviour and the development of valid propositions that researchers could use as a base for studies, and managers could use to develop best practices in their businesses, has never been harder. Hence, research in organizational behaviour is always lagging behind.

"There is considerable ambiguity regarding the exact nature of the impression management process and consequently many of the relationships described are tentative and not as well supported as others" (Gardner and Martinko, 1988, p. 336). It is not clear whether the current literature on impression management provides a guiding framework, suggests theories that explain interpersonal behaviour or merely offers glimpses of a social phenomenon that does not require extra attention from scholars and business practitioners.

The current writings shed the light on the complexity of the human behaviour and that different organizational variables can play parts as possible moderators and mediators. For example, extensive research on emotional intelligence and impression management is needed to understand if emotional intelligence leads to better outcomes as individuals more conscientiously choose their impression management strategies. Moreover, scholars connected leadership to both constructs (Cole and Rozell, 2011). "If emotional intelligence provides for effective leaders and leaders use impression management strategies, then leadership qualities can be enhanced through the connection of the two" (p. 108). Impression management is also thought to be linked to locus of control (Silvester, Anderson-Gough, Anderson and Mohamed, 2002), commitment (Shore and Wayne, 1993), performance ratings (Wayne and Liden, 1995), job satisfaction (Harris, Gallagher and Rossi, 2013), organizational citizenship behavior (Shore, Bommerand Shore, 2008) and countering discrimination (Houston III and Grandey, 2013).

Academic investigations are focusing on the individual as the unit of analysis. It is believed that individual differences are the drivers of the organization. In the current competing employment market, employees are sharpening their self-presentation skills and using different strategies to manipulate others' perceptions of them and to position themselves positively within the society targeted. The two main objectives behind this approach are the need to be liked and the need to be perceived as well skilled (Jones and Pittman, 1982).

Despite the availability of studies on impression management, all are considered tentative studies. Impression management remains to be a lucrative field for studying with relation to different organizational variables, to different cultures, and to different experimental tools. 
Consequently, the aim of the present study is to study impression management in relation to emotional intelligence and locus of control. The focus was on Egyptian full-time employees. The study is considered explorative in nature. The results will add value to the literature through addressing the dynamics of impression management in a Middle Eastern culture.

The organization of the article is as follows. First, a brief literature review on the three constructs is provided. It is then followed by the methodology followed by the researchers. Afterwards, the results are explained followed by the discussion. Finally, limitations and future research recommendations are provided.

\section{Literature Review}

\subsection{Impression Management}

Erving Goffman, who is one of the most prominent writers in Psychology and Social Psychology, was among the very few who first introduced and discussed the term Impression Management (IM). He dedicated a whole chapter in his 1956 book The Presentation of Self in Everyday Life. In his book, Goffman referred to IM as the attributes brought up by the individual to successfully create and impersonate a character. Goffman explained IM as a stage performance with performers and audiences. He also suggested that "any social establishment may be studied profitably from the point of view of impression management" (p. 152). In addition, he highlighted that studying IM should not be in vacuum as IM is typically affected by the personality, the type of interaction and the social structure. Hence, Goffman's framework is considered applicable across different social platforms.

Later, IM was defined as the process by which "individuals attempt to control the impressions others form of them" [Leary and Kowalski, (1990), p.34]. Wayne and Liden (1995) defined IM as "those behaviours individuals employ to protect their self-images, influence the way they are perceived by significant others or both" (p. 232). Mostly IM was the main concern for researchers in Psychology. Only in 1977, Wortman and Linsenmeier suggested that the findings of sociologists and psychologists on IM should be applied in organizational settings.

The IM behaviour is exhibited through different tactics. First is intimidation which reflects aggressive behaviour exhibited by the individual to convey the image of being strong, powerful and to be feared. Exemplification (known as self-focused) is the act that creates an image of decent hard-working employee who is to be loved and appreciated (Harris, Gallagher and Rossi, 2013). Third, ingratiation tactics (also known as supervisor-focused) are behaviours exhibited by individuals towards their superiors to create strong relationships, to appeal and to become liked by the supervisor (Shore, Bommerand Shore, 2008). Ingratiation is considered the mostly used strategy by individuals (Cole andRozell, 2011).

In light of the previous explanation, Thornton, Audesse, Ryckman and Burckle (2006) examined the usage of ingratiation (referred to as playing dump strategy) and self-promotion (referred to as knowing it all strategy) in a sample of participants undertaking a Psychology class. Results showed that individuals mostly use the knowing it all strategy, specifically males reported higher usage than females. The authors also showed that the usage of both strategies was correlated with low self-esteem, insecurity, and social and mental issues. 
Bolino (1999) added another two tactics, namely self-promotion and supplication. Self-promotion is simple marketing techniques individuals use to be perceived as experienced and with high knowledge. Finally, supplication is trying to be perceived as in need of help and always seeking advice.

All IM tactics are not mutually conclusive. In other words, individuals use more than one approach at the same time (Jones and Pittman, 1982 as cited in Cole and Rozell, 2011) or may diversify approaches according to the situation. In addition, IM is different from self-deception as self-deception is the tendency to think of oneself in a more favourable manner and with certain characteristics that do not exist in reality (Barrickand Mount, 1996).

Wayne and Ferris (1990) introduced a different taxonomy based on the assumption that subordinates use IM tactics to affect their supervisors' perceptions. The authors successfully developed a tool consisting of 24 items that measure IM based on three criteria. They are self-focused, job-focused and supervisory-focused tactics. Their field studies have shown that self-focused tactics did not affect supervisors' evaluations of their subordinates. However, the job-focused tactics affected the evaluations negatively, while the supervisor-focused ones affected the evaluations positively. The authors' tool was adopted in this study.

Obviously, the main goal of IM for the individual is to maximize the outcomes received and minimize any undesired consequences. IM is becoming relevant to different organizational issues such as selection, training, citizenship behaviour and leadership (Cole and Rozell, 2011).

Recognizing the need to address IM in the management field in order to explain and validate this social phenomenon in addition to constructing an explanatory framework, Gardner and Martinko (1988) provided a conceptual review of IM in the management field. Moreover, the researchers used Goffman's conceptualization as the underlying framework in presenting IM. They also highlighted that Goffman's work included a feedback loop where the individual, the situation and the behaviour interact vigorously. This reflects a social learning perspective where actors and audiences may modify their behaviours to fit the situation or to elicit more favourable responses.

The same authors also projected from research (mentioning Caldwell and O'Reilly, 1982; Weary and Arkin, 1981; Schlenker, 1980; Snyder, 1979; Christie and Geis, 1970; Crowne and Marlovv, 1964) that personality traits moderate the significance of engagement in IM. Specifically, high levels of self-monitoring awareness, Machiavellianism, social desirability and social anxiety lead to higher need to manage impressions about oneself.

Based on Gardner and Martinko (1988)'s review, IM behaviour has two types. First, there is self-presentation or the control of the information others know about the individual through verbal presentations, non-verbal cues, and physical appearances. Second, there are the indirect tactics such as using a third party to present the individual or influencing the information processing of superiors. The authors concluded with several research recommendations including the need to study the interactions between IM with other personality traits and demographic variables. 
The versatility of IM usage made scholars conclude with the multiple goal theory of IM (Cole and Rozell, 2011). Simply, individuals use IM tactics to reach several goals at once as employees tend to use IM tactics strategically, on the long-term, to achieve their needed goals (Wayne and Liden, 1995). Typically, IM tactics are studied in a career-oriented way; studying IM in relation to promotion, compensation and performance evaluations. Very recently, scholars turned to studying IM in relation to less career-oriented constructs such as job satisfaction and burnout (Harris, Gallagher and Rossi, 2013), commitment (Shore, Bommerand Shore, 2008), organizational citizenship behaviour (Shore and Wayne, 1993; Bolino, Varela, Bandeand Turnley, 2006), emotional intelligence (Cole and Rozell, 2011) and locus of control (Johnson, 1979). The last two constructed will be discussed in detail in the following two sections.

\subsection{Impression Management and Emotional Intelligence}

Emotional intelligence (EI) was coined when Salovey and Mayer whom introduced its definition as "ability to monitor one's own and other's feeling and emotions, to discriminate among them and to use this information to guide one's thinking and actions" (1990, p. 189). From the definition, it is noted that EI is not only about recognizing emotions, but also it is about using these emotions in completing tasks and solving problems. Incorporating emotional intelligence with impression management strategies is becoming a field of interest for researchers (Cole and Rozell, 2011). The same authors argue that emotionally intelligent employees are more capable of choosing effective impression management strategies than employees with less emotional intelligence awareness and training. Moreover, the use of appropriate IM tactics reflects the high EI the individual has.

IM is logically linked to EI. For emotional intelligence to be acknowledged as actual intelligence, the individual should understand his/her and others emotions correctly, be able to act based on them and achieve the needed positive outcomes. Such approach is supported by the use of effective IM tactics that will help the individual concerning the correct image and gain the positive outcomes. Cole and Rozell (2011) analysed the effect of the significance of EI on the individual's choice of IM tactics. They proposed that emotionally intelligent people will be able to understand others and different situations correctly. Hence, they will choose the most appropriate IM tactics that will yield positive results. The researchers also suggested that IM tactics of ingratiation, self-promotion and exemplification are mostly used by emotionally intelligent individuals who would refuse to engage in intimidation or supplication because of their possible drawbacks.

Jain (2012) studied the predictive ability of EI on IM. The results from an Indian middle-level managers' sample showed that, on the overall, EI has a significant impact on IM. However, the dimension of Positive Attitude about Life was negatively related to IM. Jain justified that this dimension is concerned with the general positive perception about oneself and life. Hence, those scoring high on this dimension will tend to not engage in IM behaviour. The results also indicated that different dimensions of EI affect different aspects of IM. For example, Controlled Problem Solving of EI was a positive predictor of self-focused IM. Reality awareness was a positive predictor of job-focused and supervisor-focused IM. In 
conclusion, EI enhances the individual's interpersonal skills with others. While some dimensions may evoke the individual to engage in IM to create a favourable self-image, other dimensions enhance the individual's self-confidence and stop him/her from engaging in IM tactics.

The same aforementioned author also used IM as a moderating variable between EI and organizational citizenship behaviour. However, the results showed a weaker relationship (2012). Studies on the EI-OCB relationship are on the rise as researchers find that emotionally intelligent individuals are better able to get involved in citizenship activities that help others perform better and enhance organization's productivity. Jain's study is one of the first to add IM as moderating variable to this relationship. Jain's results confirmed the proposition of Bolino (1999). While EI and IM, independently, positively affected OCB and resulted in the individual's higher engagement in citizenship behaviours, IM had a negative moderating effect on the EI-OCB relationship. This is due to the difference in the underlying motives. As individuals, aiming to only show-off and project a favourable image, tend to be overwhelmed by their personal agendas that they do not engage in real citizenship behaviours.

Emotional intelligence is without a doubt playing a significant role in organizations nowadays. While EI was and is continually studied in conjunction with different organizational variables, its interaction with impression management remains a gap that requires further studying.

\subsection{Impression Management and Locus of Control}

Locus of control explains part of the individual's personality regarding his/her belief to what extent he/she controls life's events and outcomes. Individuals with internal locus of control believe they have control over their lives and they can steer events as they prefer. However, individuals with external locus of control believe they have no control over their lives and that everything happens due to external environmental reasons. Individuals with internal locus of control are typically more successful and better achievers than individuals with external locus of control (Judge and Bono, 2001).

$\mathrm{Ng}$ and Feldman (2011) described individuals with internal locus of control as more successful in their organizations as they are skilled in negotiations, able to receive the resources they require, and with good social skills. Hence, the question whether they use impression management strategies consciously to reach their goals arises.

Johnson (1979) explored how the dimensions of locus of control affect the IM tactics used by children at schools. He proposed that individuals with internal locus of control will be more likely to engage in IM behaviour. His experiment showed that there is a form of interaction, nevertheless, neither the strength nor the direction of the relationship were identified. Additionally, his experiment provided support to the claim that motives and desired outcomes increase the chance of engaging in IM. Woolston (1970) also explored locus of control and IM among prisoners. His study also provided support to the notion that individuals with internal locus of control tend to answer surveys in a favourable manner to gain positive 
outcomes (reduction in prison time). It is worthy to note that both studies were conducted in the field of Psychology. To the researchers' knowledge, no study has explored the interaction between locus of control and IM in organizational settings. Nevertheless, it is believed that, in organizations, the opposite happens. Individuals with external locus of control will believe that they have no control over their work outcomes. Hence, they will engage in IM to positively influence the social context and the audience to receive the desired results.

Several researchers investigated IM and locus of control during the employee selection process. For example, Silvester, Anderson-Gough, Anderson and Mohamed (2002) examined how individuals use locus of control in conveying a positive impression. The researchers hypothesized and proved that when interview candidates are asked about their past failures, they attribute the failures to internal-controllable reasons to build the impression that they are responsible and motivated to their interviewers. In turn, the interviewers also evaluated the internal-controllable attributions more positive than external controllable and uncontrollable ones.

In addition, with reference to the interview questions, participants with external locus of control perceived the external-uncontrollable answers as more positively perceived than participants with internal locus of control. In addition, further analysis showed that externals use internal-controllable justifications, beside external-uncontrollable ones, equally as a defensive strategy against interviewers who perceive external-uncontrollable attributions as conveyers of negative impressions.

Peeters and Lievens (2006) reported no significant correlation between internal locus of control and self-focused IM tactics. However, the correlation between external locus of control and defensive IM tactics was significant. In addition, as the study was conducted in laboratory settings, instructions given to participants to maneuver their answers and use impression management moderated the relationship between the two variables.

However, in the field study of Mohapatra and Gupta (2010), results reflected a positive correlation between public organization's managers' internal locus of control and EI (covering aspects of managing self-emotions, social skills and utilization of emotions).

\subsection{Emotional Intelligence and Locus of Control}

In his model to predict nonviolent behavior among university students in a sample from Nigeria, Adesina (2012) found insignificant correlation between locus of control and EI. Kulshrestha and Sen (2006) found positive correlation between perceived well-being and locus of control and EI individually. In addition, both variables correlated positively with job satisfaction. The results were exclusive to managers with internal locus of control. The scholars attributed the results to the fact that individuals with internal locus of control perceive their lives to be under their control. Hence, they are proactive in solving problems and making decisions to reach their intended goals. Consequently, this provides them with happier lives and higher job satisfaction.

$\mathrm{Ng}$, Sorensen and Eby (2006) argued that internal locus of control is related to better wellbeing and that individuals with internal locus of control show better behavioral outcomes 
on the personal and professional sides. The same authors conducted a meta-analysis on over 200 articles studying locus of control. The analysis showed that internal locus of control was positively associated with the overall job satisfaction and its many sub dimensions such as pay and promotion. Internal locus of control was also positively associated with commitment, motivation, self-efficacy, and social relationships with colleagues. Nevertheless, the most important conclusion stated by the authors was that "locus of control may be related to attitudinal and behavioural outcomes at work mainly via three cognitive processes: self-evaluation of well-being, internal motivation, and a cognitive orientation of maintaining active behavioural control" (p.1072).

In a study on the attitudes of Malaysian citizens towards preventing environmental waste, Abdollahi, Mobarakeh and Karbalaei (2015) reported that individuals with high emotional intelligence and with internal locus of control reported positive attitudes towards waste prevention. The underlying reasons for the results included those with higher EI and internal LoC have consciousness, commitment to a cause, better decision making skills and responsibility for making a change.

Building upon the contributions of different scholars, the interactions between impression management, emotional intelligence and locus of control were sought after in this study. The purpose of the study was to explore the relationship between impression management, and emotional intelligence and locus of control, individually. The aim was to determine whether relationships exist and the strength of the relationships (if existed).

It is believed that the results will add value to the literature as data will be collected from a Middle Eastern culture which is rarely discussed in the literature. In addition, results will help fill the gap concerning the dynamics between impression management and other organizational constructs.

\section{Methodology}

\subsection{Sample}

The sample for this study was extracted from MBA classes at a private university in Cairo, Egypt. One-hundred and sixty questionnaires were distributed. Only one-hundred and six were returned complete with response rate of $66.3 \%$.

The sample constituted of $66 \%$ males and $34 \%$ females. The ages ranged from less than 25-30 years old (46\%), 30-40 years old (39\%), 40-50 years old (14\%) and above 50 years old (only $1 \%$ ). $71 \%$ of the sample held a Bachelor degree while the rest earned a post-graduate degree.

All participants were full-time employees with years of experience ranging from less than five years (41.5\%), 5-15 years (45.3\%) and over 15 years of experience (13.2\%). Only $21 \%$ of the participants worked in manufacturing organizations. $7.5 \%$ were from the top management, $31.1 \%$ were middle-level managers, $24.5 \%$ were first-line managers, and $36.8 \%$ held non-managerial positions. 


\subsection{Procedure}

Participants were approached at the start of their class and asked to complete the questionnaire. The questionnaires were collected at the end of the class. Participation in the study was voluntary and anonymity was assured.

\subsection{Instrument}

\subsubsection{Impression Management}

The instrument used to collect data on impression management was adopted from Wayne and Farris (1990). The instrument constituted of 24 items scored on a five-point Likert scale. The items measured impression management in terms of three sub-dimensions; self-focused, job-focused and supervisor-focused. Wayne and Farris reported their Cronbach's reliability coefficients to be above 0.80 . The Cronbach alpha was 0.83 for the current sample.

\subsubsection{Emotional Intelligence}

The tool developed by Schutte et al. (1998) was adopted in this study. 31 items were scored on five-point Likert scale. Items measured emotional intelligence based on 6 sub-dimensions; appraisal of others' emotions, appraisal of one emotions, regulations of emotions, social skills, utilization of emotions, and optimism. Schutteet al. (1998) reported Cronbach's alpha coefficient of 0.90 as opposed to 0.81 for this sample. All sub-dimensions of emotional intelligence correlated significantly positive which supports the notion that the sub-dimensions of emotional intelligence are inter-linked.

\subsubsection{Locus of Control}

The instrument developed by Spector (1988) was adopted. Initially, the instrument constituted of 16 items. However, two items were removed as they were redeemed redundant and inappropriate for the selected sample. The Cronbach Alpha coefficient was 0.70 for the 14 items. Higher scores on the instrument indicated externality.

\section{Results}

Table 1: Descriptive Statistics of the Sample

\begin{tabular}{|l|c|c|c|c|}
\hline & Means & Standard Deviation & Minimum & Maximum \\
\hline $\begin{array}{l}\text { Job-focused } \\
\text { impression } \\
\text { management }\end{array}$ & 2.85 & 0.48 & 1.83 & 4.25 \\
\hline $\begin{array}{l}\text { Self-focused } \\
\text { impression } \\
\text { management }\end{array}$ & 3.66 & 0.52 & 2.20 & 4.80 \\
\hline $\begin{array}{l}\text { Supervisor-focused } \\
\text { impression }\end{array}$ & 3.15 & 0.57 & 1.71 & 4.57 \\
\hline
\end{tabular}




\begin{tabular}{|c|c|c|c|c|}
\hline management & & & & \\
\hline $\begin{array}{l}\text { Impression } \\
\text { Management }\end{array}$ & 3.22 & 0.43 & 1.94 & 4.28 \\
\hline $\begin{array}{l}\text { Appraisal of others' } \\
\text { emotions }\end{array}$ & 3.52 & 0.52 & 2.00 & 4.83 \\
\hline $\begin{array}{l}\text { Appraisal of own } \\
\text { emotions }\end{array}$ & 3.79 & 0.51 & 2.20 & 5.00 \\
\hline $\begin{array}{l}\text { Regulation of } \\
\text { emotions }\end{array}$ & 3.81 & 0.49 & 2.60 & 5.00 \\
\hline Social skills & 3.82 & 0.48 & 2.40 & 4.80 \\
\hline $\begin{array}{l}\text { Utilization of } \\
\text { emotions }\end{array}$ & 3.72 & 0.40 & 2.67 & 4.83 \\
\hline Optimism & 3.98 & 0.45 & 2.75 & 5.00 \\
\hline $\begin{array}{l}\text { Emotional } \\
\text { Intelligence }\end{array}$ & 3.77 & 0.32 & 2.97 & 4.68 \\
\hline Locus of Control & 2.52 & 0.42 & 1.14 & 3.29 \\
\hline
\end{tabular}

Table one presents the averages (arithmetic means) of the three variables under investigation. The overall average of impression management was $3.22(s=0.43)$. Participants reported using self-focused tactics the most as evident by the highest mean. Emotional intelligence had an overall average of $3.77(\mathrm{~s}=0.32)$ with optimism, regulation of emotions and social skills having the highest averages reflecting the characteristics of emotional intelligence participants mostly had. Finally, locus of control had an overall average of $2.52(s=0.42)$ which is lower than the means of the other two variables. This indicates that participants mostly had (or claimed to have) internal locus of control.

Table two provides the correlation matrix which explains the correlation between the main variables and their sub-dimensions. The Spearman Rank Order Correlation was calculated to explore the strength and the direction of the relationships between impression management, and emotional intelligence and locus of control and their sub-dimensions.

The correlation between impression management and emotional intelligence proved to be weak and non-significant $[\mathrm{r}=0.08, \mathrm{n}=106, \mathrm{p}>0.05]$. Nevertheless, the disaggregation of the variables showed mixed results. Significant positive correlations were found between social skills (element of EI) and self-focused IM ( $p<0.01$ ), optimism (element of EI) and self-focused IM, and optimism and supervisor-focused IM ( $p<0.05)$. 


\section{Macrothink}

However, the correlation between impression management and locus of control was significantly positive, yet weak $[\mathrm{r}=0.19, \mathrm{n}=106, \mathrm{p}<0.05]$ indicating that individuals with external locus of control reported higher usage of impression management tactics than individuals with internal locus of control. The analysis specifically showed strong significant correlation between job-focused IM tactics and locus of control $(r=0.4, p<0.01)$.

Finally, Spearman rho's reflected insignificant, however negative, correlation between emotional intelligence and locus of control $[\mathrm{r}=-0.14, \mathrm{n}=106, \mathrm{p}>0.05]$. Nonetheless, the negative correlations indicate that emotional intelligence is associated with internal locus of control. In addition, there was a significant relationship between regulation of emotions (element of EI) and locus of control $[\mathrm{r}=-0.25, \mathrm{p}<0.05]$.

Further analysis of the correlation between impression management and locus of control (controlling for emotional intelligence) was conducted. Results of the partial correlation showed that the strength of the correlation was $r=0.187(\mathrm{p}<0.05)$ which is almost identical to the results obtained from Spearman rho's. Hence, any possible moderating effect was excluded. 


\section{Macrothink}

International Journal of Human Resource Studies

ISSN 2162-3058

1 Table 2: Correlations of the main variables and subcomponents (Spearman's rho)

\begin{tabular}{|c|c|c|c|c|c|c|c|c|c|c|c|c|}
\hline & $\begin{array}{l}\text { Job-focused } \\
\text { impression } \\
\text { management }\end{array}$ & $\begin{array}{l}\text { Self-focused } \\
\text { impression } \\
\text { management }\end{array}$ & $\begin{array}{l}\text { Supervisor-focused } \\
\text { impression } \\
\text { management }\end{array}$ & $\begin{array}{l}\text { Impression } \\
\text { Management }\end{array}$ & $\begin{array}{l}\text { Appraisal } \\
\text { of others' } \\
\text { emotions }\end{array}$ & $\begin{array}{l}\text { Appraisal } \\
\text { of own } \\
\text { emotions }\end{array}$ & $\begin{array}{l}\text { Regulation } \\
\text { of } \\
\text { emotions }\end{array}$ & $\begin{array}{l}\text { Social } \\
\text { skills }\end{array}$ & $\begin{array}{l}\text { Utilization } \\
\text { of } \\
\text { emotions }\end{array}$ & Optimism & $\begin{array}{l}\text { Emotional } \\
\text { Intelligence }\end{array}$ & $\begin{array}{l}\text { Locus } \\
\text { of } \\
\text { Control }\end{array}$ \\
\hline $\begin{array}{l}\text { Job-focused } \\
\text { impression } \\
\text { management }\end{array}$ & 1.000 & & & & & & & & & & & \\
\hline $\begin{array}{l}\text { Self-focused } \\
\text { impression } \\
\text { management }\end{array}$ & $.566^{* * *}$ & 1.000 & & & & & & & & & & \\
\hline $\begin{array}{l}\text { Supervisor-focused } \\
\text { impression } \\
\text { management }\end{array}$ & $.419^{* *}$ & $.506^{* *}$ & 1.000 & & & & & & & & & \\
\hline $\begin{array}{l}\text { Impression } \\
\text { Management }\end{array}$ & $.767^{* *}$ & $.853^{* *}$ & $.798^{* * *}$ & 1.000 & & & & & & & & \\
\hline $\begin{array}{l}\text { Appraisal of } \\
\text { others' emotions }\end{array}$ & -.016 & -.079 & .004 & -.054 & 1.000 & & & & & & & \\
\hline $\begin{array}{l}\text { Appraisal of own } \\
\text { emotions }\end{array}$ & -.188 & -.173 & -.045 & -.155 & $.332^{* *}$ & 1.000 & & & & & & \\
\hline
\end{tabular}




\begin{tabular}{|c|c|c|c|c|c|c|c|c|c|c|c|c|}
\hline $\begin{array}{l}\text { Regulation of } \\
\text { emotions }\end{array}$ & -.126 & .046 & .087 & .029 & $.258^{* *}$ & $.506^{* *}$ & 1.000 & & & & & \\
\hline Social skills & .045 & $.253^{* *}$ & .191 & $.223^{*}$ & $.316^{* *}$ & $.310^{* *}$ & $.346^{* *}$ & 1.000 & & & & \\
\hline $\begin{array}{l}\text { Utilization of } \\
\text { emotions }\end{array}$ & .013 & .180 & .107 & .141 & $.380^{* *}$ & $.436^{* *}$ & $.567^{* *}$ & $.360^{* *}$ & 1.000 & & & \\
\hline Optimism & -.017 & $.205^{*}$ & $.212^{*}$ & .174 & .094 & $.227^{*}$ & $.274^{* *}$ & $.364^{* *}$ & $.312^{* *}$ & 1.000 & & \\
\hline $\begin{array}{l}\text { Emotional } \\
\text { Intelligence }\end{array}$ & -.089 & .095 & .130 & .076 & $.580^{* *}$ & $.699^{* *}$ & $.728^{* *}$ & $.642^{* *}$ & $.755^{* *}$ & $.541^{* *}$ & 1.000 & \\
\hline Locus of Control & $.362^{* *}$ & .106 & .008 & $.191^{*}$ & -.023 & -.155 & $-.246^{*}$ & -.006 & -.048 & -.041 & -.135 & 1.000 \\
\hline
\end{tabular}

$2 \quad * p$ is significant at 0.05

$3 \quad * * p$ is highly significant at 0.01 


\section{Discussion}

The aim of this study was to explore the interaction between impression management and other organizational variables, specifically emotional intelligence and locus of control. The study was explorative in nature without any underlying assumptions due to the fact that research on impression management is still in the infancy stage. Despite numerous attempts by researchers to investigate impression management, significant research gaps are evident. The study was conducted on a group of 106 full-time employees taking MBA classes in a private university situated in Cairo, Egypt.

Concerning the relationship between impression management and emotional intelligence, the researchers failed to demonstrate a significant relationship between the overall concepts with the approached sample. However, the analyses of the interrelationships between the sub-dimensions of impression management and emotional intelligence exposed different evidence. First, there was a positive relationship between social skills (element of EI) and self-focused IM tactics. The results coincide with the definitions of social skills and self-focused impression management tactics. Social skills are about relationship management to build strong relationships with others, to be kind, nurturing and influential. Self-focused impression management is using tactics to build and improve the self-image in order to be liked by others in the social context. Hence, using social skills is one tactic used by actors to influence audiences' perceptions. With reference to organizational setting, tactics include avoiding conflicts, solving complaints, engaging in organizational citizenship behavior, preferring teamwork, and helping and inspiring others.

Second, positive relationships were also identified between optimism (element of EI), and self-focused and supervisor-focused IM tactics. Optimism is a powerful skill for survival in organizations. Optimism influences individual's physical and psychological wellbeing which affects performance at work. Accordingly, it is logical to assume that optimism will be correlated with impression management tactics dedicated to self and supervisor as optimism assists in setting high organizational goals, facing obstacles and celebrating success. Consequently, positive impressions about the employees themselves will be created. In addition, perceptions of supervisors will be influenced in a positive manner. Nevertheless, the question arises whether emotionally intelligent individuals use IM tactics consciously.

Concerning impression management and locus of control, there was a significant positive relationship between them indicating that employees with external locus of control reported higher usage of impression management tactics than employees with internal locus of control. Specifically, strong relationship was found between job-focused IM tactics and locus of control. The results match all previous discussions on locus of control that individuals with internal locus of control believe that they control their lives and they can influence the outcomes. Hence, they will not engage in impression management to affect the social context. Instead, they will tend to work and fulfill their obligations. In addition, they will not risk engaging in impression management due to its possible risks. On the other hand, externality corresponds to using IM tactics to present oneself in a specific mode.

Finally, the relationship between emotional intelligence and locus of control is negative, 
despite its insignificance. The results also match previous research that individuals who have emotional intelligence are mostly with internal locus of control. In the organizational context, employees with high emotional intelligence are able to identify and manage their feelings. In addition, they understand others' sentiments. They are able to regulate others and build strong social relationships. In addition, their optimism enable them to set goals and fulfill them. Simultaneously, this requires the employees to have internal locus of control to be able to create and steer change.

\section{Limitations and Future Research Directions}

The current research fell short in certain aspects. First, the sample size is small relative to the population size. Second, the characteristics of the sample were not adequately diverse. Third, some of the results were insignificant. One way to justify the results provided for in the current study is that IM is heightened during certain contexts like in an interview setting, for example. The current study failed to grasp a certain setting where using IM is amplified. Forth, differentiating between IM tactics and natural responses is indefinite; it is complicated to attribute a gesture to IM tactic or individual's personality. Fifth, self-reported measures have the risk of participants having social desirability bias. Therefore, they may not answer the questions truly and only provide answers that they think will be likeable.

For future studies, it is recommended to conduct experiments in actual settings where using impression management tactics is most likely, for example, during the selection process of job candidates. Larger sample sizes are recommended with a focus on diversity in demographics, cultures and types of organizations. Samples should be collected from different industries as well (Jain, 2012) to allow for comparisons. Finally, it is recommended to study impression management in relation to different organizational constructs.

\section{References}

Abdollahi, A. Mobarakeh, M. R. V.Karbalaei, S. (2015). Locus of control, hardiness, and emotional intelligence as predictors of waste prevention behaviours. Romanian Journal of Applied Psychology.17(1), 8-16.

Adesina, O. J. (2012). Emotional intelligence, locus of control and conflict handling skills as predictors of non-violent behavior among university students in South-Western NigeriaIfe PsychologIA.20(2), 31-38.

Barrick, M. R. Mount, M. K. (1996). Effects of impression management and self-deception on the predictive validity of personality constructs. Journal of Applied Psychology. 81(3), 261-272.https://doi.org/10.1037/0021-9010.81.3.261

Bolino, M.C. (1999). Citizenship and impression management: Good soldiers or good actors?. The Academy of Management Review.24(1), 82-98.https://doi.org/10.5465/AMR.1999.1580442

Bolino, M. C. Varela, J. A. Bande, B.Turnley, W.H. (2006). The impact of impression-management tactics on supervisor ratings of organizational citizenship behaviour. 
Journal of Organizational Behaviour. 27, 281-297.https://doi.org/10.1002/job.379

Cole, A. Y., \&Rozell, E. J. (2011). Emotional intelligence and impression management: A theoretical framework.Insights to a Changing World Journal, 1, 93-114.

Gardner, W. L.Martinko, M. J. (1988). Impression management in organizations. Journal of Management. 14(2), 321-338.https://doi.org/10.1177/014920638801400210

Goffman, E. (1956). The Presentation of Self in Everyday Life, University of Edinburgh, Social Sciences Research Centre.

Harris, K. J. Gallagher, V. C.Rossi, A.M. (2013). Impression management (IM) behaviors, IM culture, and Job Outcomes. Journal of Managerial Issues.XXV(2), 154-171.

Houston III, L.Grandey, A.A. (2013). What we don't know can hurt us: A call for stereotype-congruent impression management tactics. Industrial and Organizational Psychology. 6(4), 433-437.https://doi.org/10.1111/iops.12080

Jain, A. K. (2012). Does emotional intelligence predict impression management?.Journal of Organizational Culture, Communications and Conflict.16(2), 11-24.

Johnson, D.A. (1979). The Role of Internal-External Locus of Control in the Use of Impression Management by School-Aged Children. (Doctoral dissertation). University of Montana.

Jones, E. E. Pittman, T. S. (1982). Toward a general theory of strategic self-presentation', in Suls, J. (Ed.).Psychological Perspectives of the Self, Hillsdale, NJ: Eribaum, pp. 231-261.

Judge, T. A. Bono, J. E. (2001). Relationship of core self-evaluations traits-self-esteem, generalized self-efficacy, locus of control, and emotional stability - with job satisfaction and job performance: A meta-analysis.Journal of applied Psychology.86(1), 80.https://doi.org/10.1037/0021-9010.86.1.80

Kulshrestha, U.Sen, C. (2006). Subjective wellbeing in relation to emotional intelligence and locus of control among executives. Journal of Indian Academy of Applied Psychology.32(2), 93-98.

Leary, M. R. Kowalski, R.M. (1990). Impression management: A literature review and two-component model. Psychological Bulletin.107(1), 34-47.https://doi.org/10.1037/0033-2909.107.1.34

Mohapatra, M. Gupta, A. (2010). Relationship of emotional intelligence with work values and internal locus of control: A study of managers in a public sector organization. Vilakshan: The XIMB Journal of Management. 7(2), 1-20.

Ng, T. W. H. Feldman, D. C. (2011). Locus of control and organizational embeddedness. Journal of Occupational and Organizational Psychology. 84, 173-190.https://doi.org/10.1348/096317910X494197

Ng, T. W. H. Sorensen, K. L.Eby, L. T. (2006). Locus of control at work: A 
Peeters, H. Lievens, F. (2006). Verbal and nonverbal impression management tactics in behavior description and situational interviews.International Journal of Selection and Assessment. 14(3), 206-222.https://doi.org/10.1111/j.1468-2389.2006.00348.x

Salovey, P. Mayer, J. D. (1990). Emotional intelligence.Imagination, Cognition and Personality. 9(3), 185-211.https://doi.org/10.2190/DUGG-P24E-52WK-6CDG

Shore, L. M. Wayne, S.J. (1993). Commitment and employee behaviour: Comparison of affective commitment and continuance commitment with perceived organizational support. Journal of Applied Psychology. 78(5), 774-780.https://doi.org/10.1037/0021-9010.78.5.774

Shore, T. H.Bommer, W. H.Shore, L.M. (2008). An integrative model of managerial perceptions of employee commitment: Antecedents and influences on employee treatment.Journal of Organizational Behavior. 29, 635-655.https://doi.org/10.1002/job.516

Silvester, J. Anderson-Gough, F. M. Anderson, N. R. Mohamed, A. R. (2002). Locus of control, attributions and impression management in the selection interview.Journal of Occupational and Organizational Psychology. 75, 59-76.https://doi.org/10.1348/096317902167649

Thornton, B. Audesse, R. J. Ryckman, R. M.Burckle, M. J. (2006). Playing dump or knowing it all: Two sides of an impression management coin.Individual Differences Research.4(1), $37-45$.

Wayne, S. J. Farris, G. R. (1990). Influence tactics, affect, and exchange quality in supervisor-subordinate interactions: A laboratory experiment and field study.Journal of Applied Psychology. 75(5), 487-499.https://doi.org/10.1037/0021-9010.75.5.487

Wayne, S. J.Liden, R.C. (1995). Effects of impression management on performance ratings: A longitudinal study.Academy of Management Journal. 38(1), 232-260.https://doi.org/10.2307/256734

Woolston, W.D. (1970). Internal-External Locus of Control and Impression Management among Inmates of the Montana State Prison. (MSc Thesis). University of Montana.

Wortman, C. B.Linsenmeier, J. A. (1977). Interpersonal attraction and techniques of ingratiation in organizational settings', in Staw, B. M. and Salancik, G. R. (Eds.), New Directions in Organizational Behaviour, Chicago: St. Clair Press, pp.133-178 


\section{Macrothink}

International Journal of Human Resource Studies

ISSN 2162-3058

\section{Copyright Disclaimer}

Copyright for this article is retained by the author(s), with first publication rights granted to the journal.

This is an open-access article distributed under the terms and conditions of the Creative Commons Attribution license (http://creativecommons.org/licenses/by/3.0/). 